\title{
匂いセンサと嗅覚ディスプレイ
}

中本高道

\section{Odor Sensing System and Olfactory Display}

\author{
Takamichi Nakamoto \\ Precision and Intelligence Laboratory, Tokyo Institute of Technology; R2-5 4259 Nagatsuda, \\ Midoroi-ku, Yokohama 226-8503, Japan.
}

(Received August 31, 2013)

\begin{abstract}
In this review, an odor sensing system and an olfactory display are introduced into people in pharmacy. An odor sensing system consists of an array of sensors with partially overlapping specificities and pattern recognition technique. One of examples of odor sensing systems is a halitosis sensor which quantifies the mixture composition of three volatile sulfide compounds. A halitosis sensor was realized using a preconcentrator to raise sensitivity and an electrochemical sensor array to suppress the influence of humidity. Partial least squares (PLS) method was used to quantify the mixture composition. The experiment reveals that the sufficient accuracy was obtained. Moreover, the olfactory display, which present scents to human noses, is explained. A multi-component olfactory display enables the presentation of a variety of smells. The two types of multi-component olfactory display are described. The first one uses many solenoid valves with high speed switching. The valve $\mathrm{ON}$ frequency determines the concentration of the corresponding odor component. The latter one consists of miniaturized liquid pumps and a surface acoustic wave (SAW) atomizer. It enables the wearable olfactory display without smell persistence. Finally, the application of the olfactory display is demonstrated. Virtual ice cream shop with scents was made as a content of interactive art. People can enjoy harmony among vision, audition and olfaction. In conclusion, both odor sensing system and olfactory display can contribute to the field of human health care.
\end{abstract}

Key words_ odor sensing system; olfactory display; pattern recognition; halitosis; preconcetrator; surface acoustic wave (SAW) streaming

\section{1.はじめに}

匂いセンサは匂いの種類を識別したり，匂い強度 を出力するセンサであり, 食品, 飲料, 環境計測, 医療等の分野で必要とされている. ガスクロマトグ ラフィーのような分析機器や官能検査に代わって迅 速かつ簡便に匂いを検査する方法が望まれている. この分野の研究は 4 半世紀に渡つて世界的に行われ ており, 研究者人口も多い。ヨーロッパ等では electronic nose と呼ばれ，センサのデバイスから信 号処理法に至るまでの研究が行われている. 1,2)

一方，近年では嗅覚ディスプレイという香りを発 生させる装置の研究が行われるようになってき

The author declares no conflict of interest.

東京工業大学精密工学研究所（干226-8503 横浜市緑区

長津田 4259, R2-5)

e-mail: nakamoto.t.ab@m.titech.ac.jp

本総説は, 日本薬学会第 133 年会シンポジウム S30-

302 で発表した内容を中心に記述したものである.
た. ${ }^{3,4)}$ 従来からある olfactometer よりも簡便に多様 な香りを発生させることを目指したもので，人工現 実感の分野を中心に研究が行われている．研究者人 口は匂いセンサほど多くはないが日本を中心に論文 発表等が増えつつある。 2013 年 4 月には嗅覚ディ スプレイを中心にした初めての国際会議 Digital Olfaction Societyがドイツ・ベルリンで開催され，こ の分野が少しずつ認知されつつある. 5)

本稿では匂いセンサ及び嗅覚ディスプレイに関す る最新の話題をいくつか紹介したい.

2. 匂いセンサの仕組み

生体嗅覚では，嗅覚受容体で匂い物質の部分的な 構造を認識する。 その様子を Fig. 1 に示す。 それ ぞれの嗅覚受容体で認識する構造が異なるので, 複 数の嗅覚受容体の応答を嗅覚神経系でパターン認識 することで匂いの種類の識別が可能になる. ${ }^{6}$

そこで，匂いセンサでは特性の異なる複数センサ 


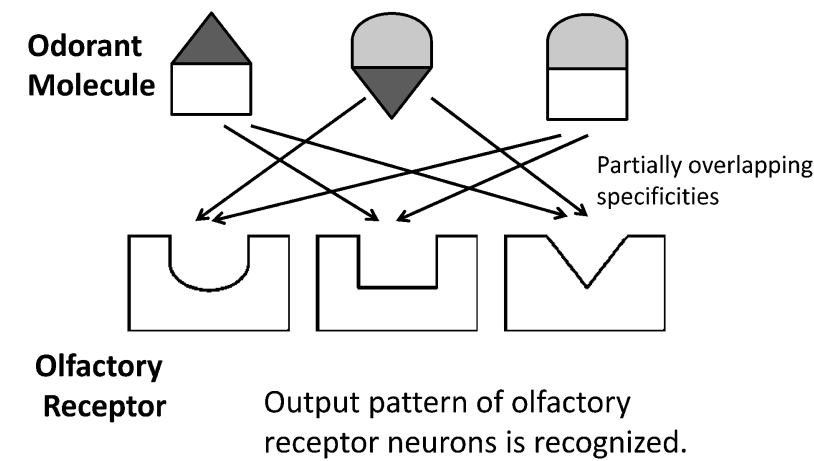

Fig. 1. Principle of Odor Discrimination in Biological Systems

の応答パターンをパターン認識することで, 匂い種 類の識別を行う。センサデバイスとしては，半導体 ガスセンサを始めとして水晶振動子センサ, surface acoustic wave (SAW) センサ，導電性高分子セ ンサ等様々なセンサが使用される.7)(ずれの場合 も生体嗅覚と全く同じ仕組みでセンシングしている わけではないが, 複数センサ出力をパターン認識し て匂い識別を行う点は同じである.

パターン認識の手法としては, 判別分析法などの 多変量解析やニューラルネットワークが用いられ る. ${ }^{8)}$ 近年は support vector machine (SVM) がよく 使用されるようになった. ${ }^{9)}$

最近の話題としては，センサデバイスとして嗅覚 受容体や嗅細胞そのものを使用する研究が挙げられ る.これらのセンサは，匂いバイオセンサとか bioelectronic nose と呼ばれる. ${ }^{10,11)}$

\section{3. 匂いセンサの応用}

匂いセンサの研究の一例として，口臭センサをと り上げる. 口臭センサは口腔内に残った食べ物の匂 いを検出するものではなく, 人の口腔そのものから 発生した匂いを検出するものである．匂いは舌苔等 に由来すると言われ，舌を清掃するために舌ブラシ というブラシもある。この口臭の主な成分は揮発性 硫化物（volatile sulfide compound; VSC）であり, その中で methyl mercaptan, hydrogen sulfide, dimethyl sulfide の 3 種類が重要である. ${ }^{12)}$ そこで，こ の 3 種類の VSC を検出し, その混合比を求める口 臭センサを開発した. ${ }^{13)}$

口臭センサは subppm 程度の濃度の混合ガスを測 定する必要がある。また， 口腔内は湿度が高く湿度 の影響を受けずに低濃度ガスを測定したい。そこ

で，低濃度のガスを湿度の影響を受けずに測定する ために，濃縮管と電気化学センサを組み合わせたシ ステムを製作した.

濃縮管とは Fig. 2 に示すように吸着剂を詰めて ヒー夕線を巻いたもので，吸着剤に匂いを吸着させ て蓄積しヒータ加熱により脱着させ匂い濃度を高め てセンサに供給するものである. ${ }^{14)}$ 吸着剤は顆粒状 のもので，濃縮管に流すガスフローで流されないよ うに濃縮管の両端にガラス繊維を詰める。吸着剤に は様々な種類があり，中には水分をほとんど吸着し

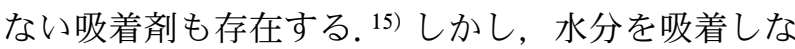
い吸着剤は硫化物もあまり吸着しないために，結局 最も一般的な吸着剂である活性炭を使用した。

電気化学センサは電解液に作用極, 対極, 参照極 の 3 種類の電極を入れたもので，隔膜を介してガス を溶液中に導入する。 そして，設定電位より大きな 酸化還元電位を有するガスがくると電流が流れ，そ の電流を検出する，電解液の主要成分は水のため に，水分に対する感度は有さずに湿度に依存しない センサを実現できる，ガスセンサの多くは湿度依存 性を有し口臭センサを実現する上で湿度依存性の克 服が大きな課題となるが，このセンサはその点大き な長所を有する。

そして，設定電位や電極材料を変えて特性の異な る複数センサを用意し，センサアレイを構成する. ここでは市販品 (Multiwarn II, Draeger Safety Japan) の電気化学ガスセンサ 3 種類 $\left(\mathrm{SO}_{2}\right.$ 用, 硫化水素 用，硫化物全般用）を使用した。電気化学センサは 比較的優れた選択性を有するが，上記 3 種類の VSC に対する完全な選択性は有していない。しか し，パターン認識の技術を用いればこれらのVSC を識別することが可能である.

電気化学ガスセンサの応答はほぼ線形重ね合わせ が成り立つことが知られている。デー夕解析手法と して最も基礎的な方法は重回帰分析法である．本研 究では, もう少し多重共線性に優れた性能を持つ

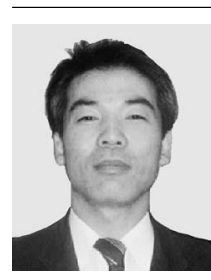

中本高道
1984 年東京工業大学大学院修士課程修 了. 同年日立製作所入社. 1987 年東京 工業大学助手, 1993 年同大学助教授を 経て現在同大教授。工学博士。19961997 年米国パシフィックノースウェス 卜研究所客員研究員. 知覚情報処理, ヒューマンインタフェース, 計測工学 の研究に従事. 


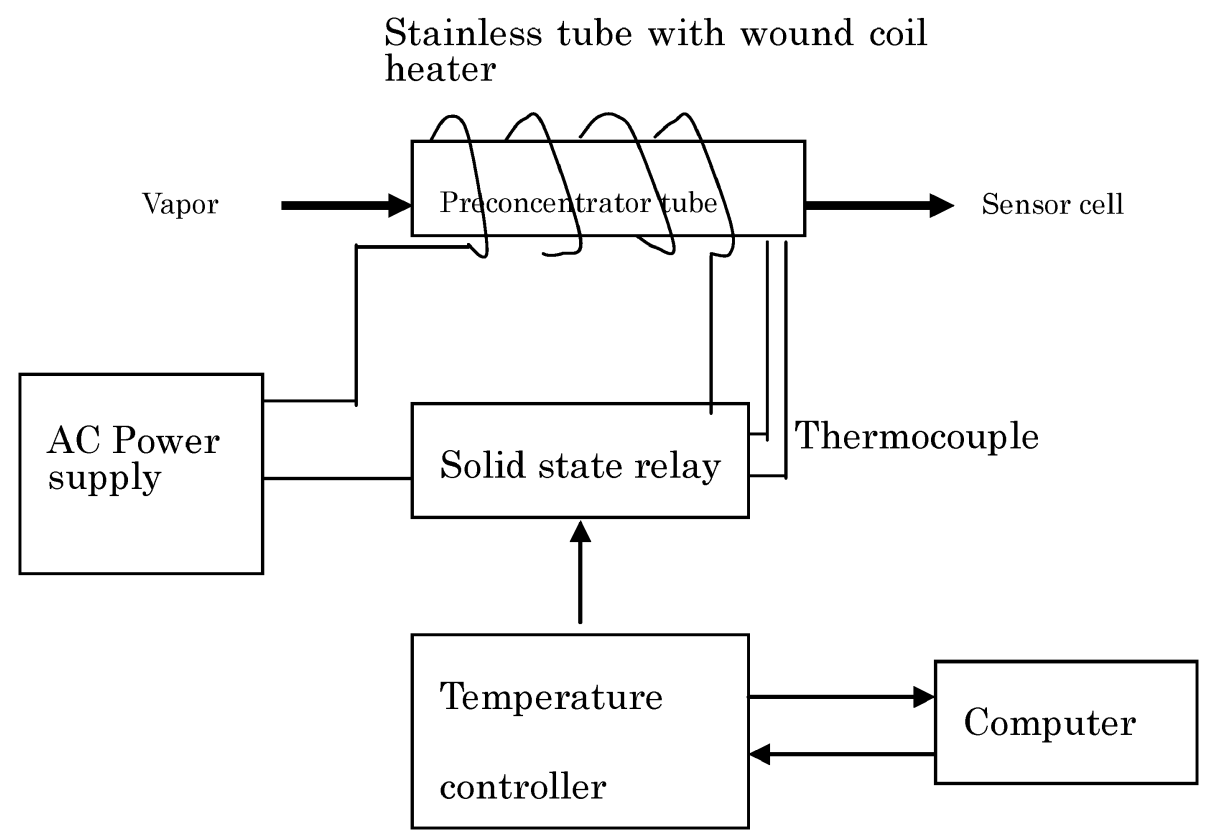

Fig. 2. Preconcentrator System

partial least squares (PLS) 法を使用した. ${ }^{16)}$ ここで, 3 種類の VSC を混合したテスト用の混合ガスを用 いて，混合臭の濃度定量の性能を調べた。混合ガス はサンプリングバッグに別々にガスを作製してマス フローコントローラで流量比を制御して混合した. そして，1 個のデータを除いて他のすべてのデータ を訓練データとして，訓練に使用していない 1 個の デー夕を評価データとして cross validation で定量 してその精度を評価した．各成分毎に定量濃度と実 際の濃度の関係を Figs. 3 (a)-(c) に示す。対角線と プロットの間の距離が短いほどよく定量できている ことがわかる．同図より若干のプロットを除きほぼ 対角線に近いところに実験データがプロットされて おり本測定システムを用いて口臭原因物質の定量を 行うことができることがわかった.

口臭センサでは高湿度下で低濃度の混合ガスの濃 度定量がその課題であった. 大気中の匂いのセンシ ングには様々な外乱があり，外乱にロバストな匂い センシング手法を開発することが課題である. ${ }^{17)} \square$ バスト匂いセンシングは，匂いセンサを実用化して いく上で重要なポイントである.

\section{4. 嗅覚ディスプレイ}

センシングではなく人の鼻に香りを提示する装置 を嗅覚ディスプレイという. ${ }^{18,19)}$ 従来から人の嗅覚 をテストするためのオルファクトメータという装置 はあったが，もっと簡便で多様な香りを提示する装
置の開発が進んでおり主に人工現実感の分野で研究 が行われている。2013 年には Digital Olfaction Society という学会がベルリンで開かれ，現在開発 されている嗅覚ディスプレイが一堂に会してデモ展 示が行われた. ${ }^{20)}$

嗅覚ディスプレイは香り発生方法や人の鼻への匂 い供給方法に工夫を凝らしたものが提案されている が，多様な香りを生成するためには香りの調合技術 が重要である。ここでは多成分調合型嗅覚ディスプ レイを紹介する．Figure 4 は電磁弁高速開閉方式に よる嗅覚ディスプレイである，電磁弁は流体回路の スイッチのようなもので，この開閉頻度を制御する ことで任意の濃度の香りを作り出すことができる. この仕組みを多成分に拡張して現在までに最大 32 成分調合可能な装置も製作されている. ${ }^{21)}$ Figure 4 は 13 成分調合可能な装置であり既にいくつかの大 学や企業で使用されている.

電磁弁高速開閉方式はたくさんの成分を調合する のに優れているが，低揮発性香気成分の香り発生に 関して十分な速度で香り発生と消去ができない問題 がある．低揮発性香気成分は配管内に香りが残り易 く配管をなくすことはできない，そこで，電磁弁に 代わつて小型ポンプと弾性表面波霧化器を用いた小

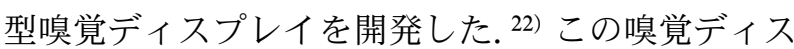
プレイは残香の問題を解決するためのものである. 小型液体ポンプは電気浸透流現象を利用したもので 


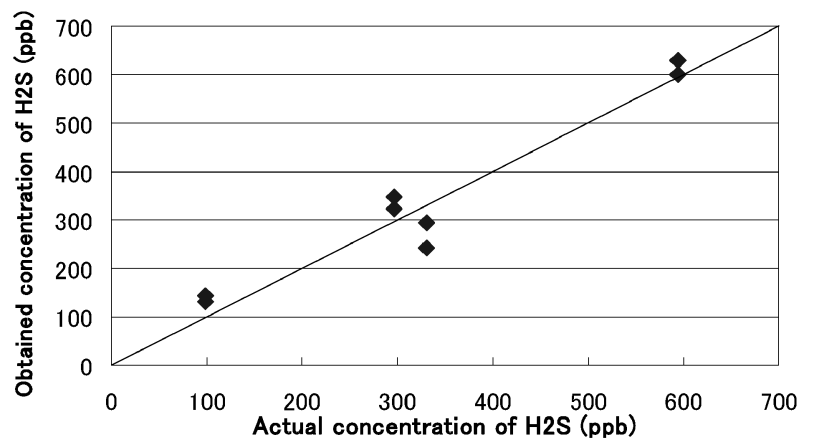

(a)

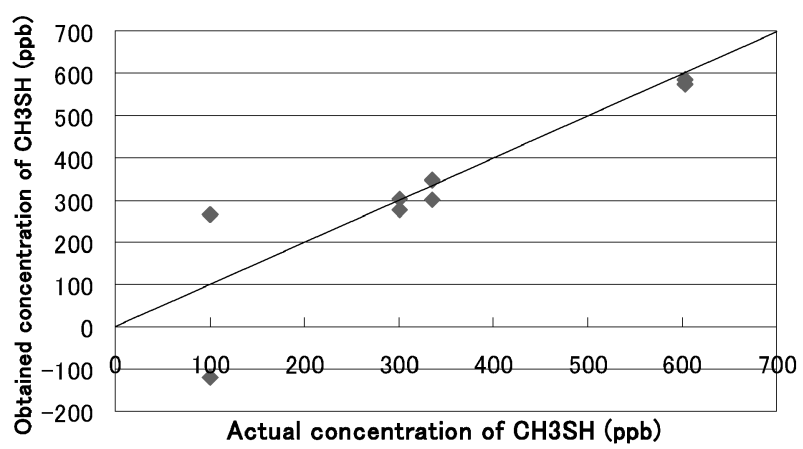

(b)

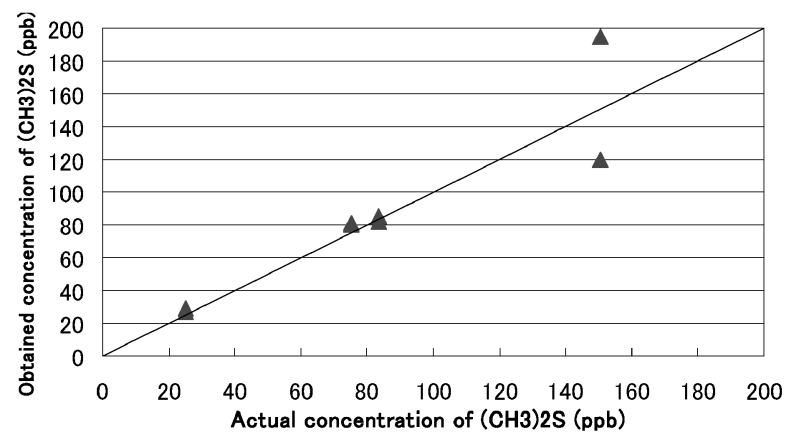

( c )

Fig. 3. Quantification Result of Ternary Mixture Composed of VSCs

(a) hydrogen sulfide, (b) methyl mercaptan and (c) dimethyl sulfide.

サイズが小型（直径 $6 \mathrm{~mm}$ ，高さ $11.5 \mathrm{~mm}$ ，液溜込 み）にもかかわらず細いチューブを通して液体を運 ぶことができる.

このポンプからステンレス細管を通して微少量の 液体を弾性表面波デバイスに滴下し, acoustic streaming 現象を利用して瞬時に霧化する. ${ }^{23)}$ そうすると 瞬間的に鼻元に香りが提示される。霧化は鼻元で行 い気体を運ぶ配管を用いないために残香の問題がな い.これらのデバイスを用いて 8 成分の香りを調合 する小型嗅覚ディスプレイを製作した. ${ }^{24)} 8$ 個の電

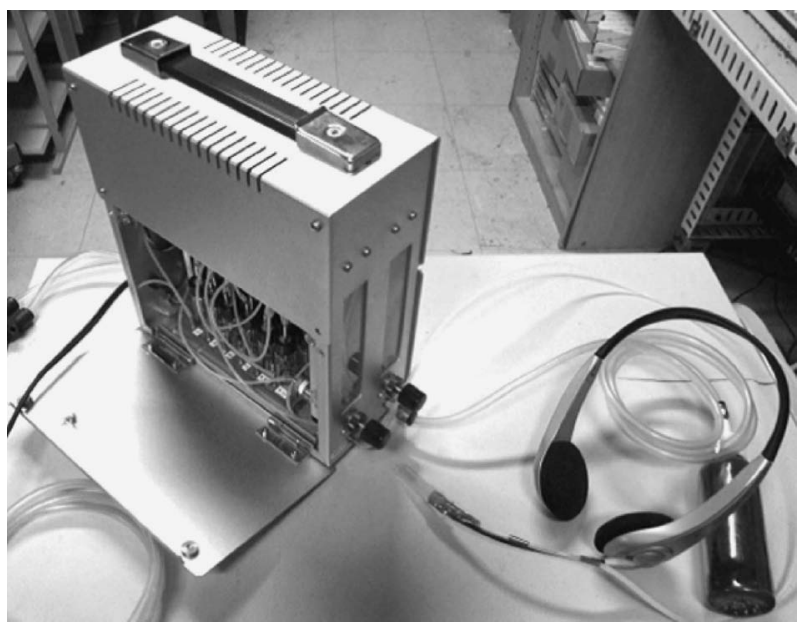

Fig. 4. Photo of Multi-component Olfactory Display Available from Ono Denki.

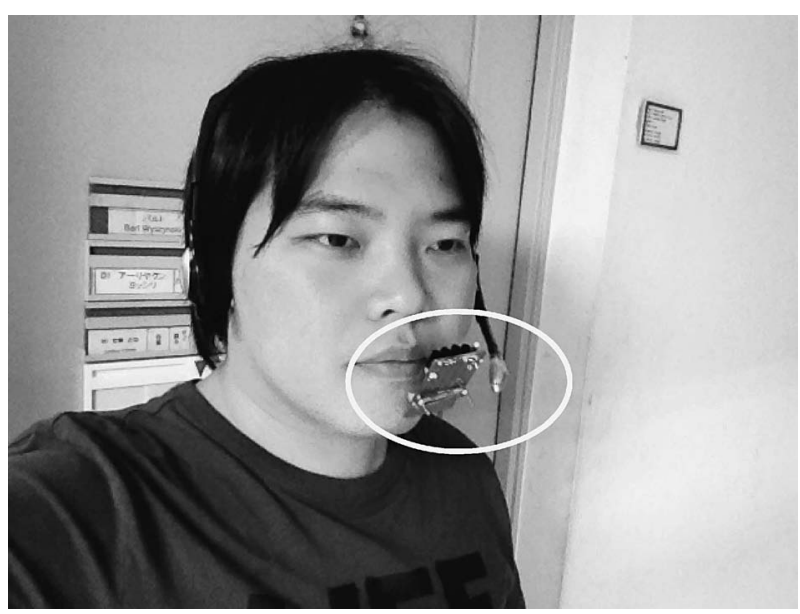

Fig. 5. Olfactory Display Using Electroosmotic Pumps and Surface Acoustic Wave Atomizer

気浸透流ポンプと弾性表面波霧化器を $37.4 \times 56.7$ $\mathrm{mm}$ のプリント基板上に実装した。 人がこの嗅覚デ イスプレイを装着した写真を Fig. 5 に示す。この サイズはクレジットカードよりも小型であるが，今 後周辺回路も含めた小型化が必要である.

これらの嗅覚ディスプレイを用いて様々なコンテ ンツを作成することができる，映画に香りをつけた

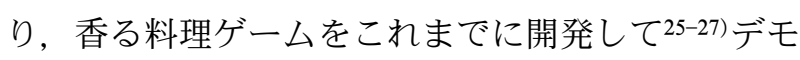
ンストレーションを行ってきた。本稿では Virtual ice cream shop について紹介する. ${ }^{28)}$

体験者があたかも店のカウンターにいるかのよう にして好きなフレーバーを選び，そして選んだフ レーバーの匂いに最適と思える音色を割り当て，そ の状態で鍵盤を弾くとヘッドセットから，音と香り 


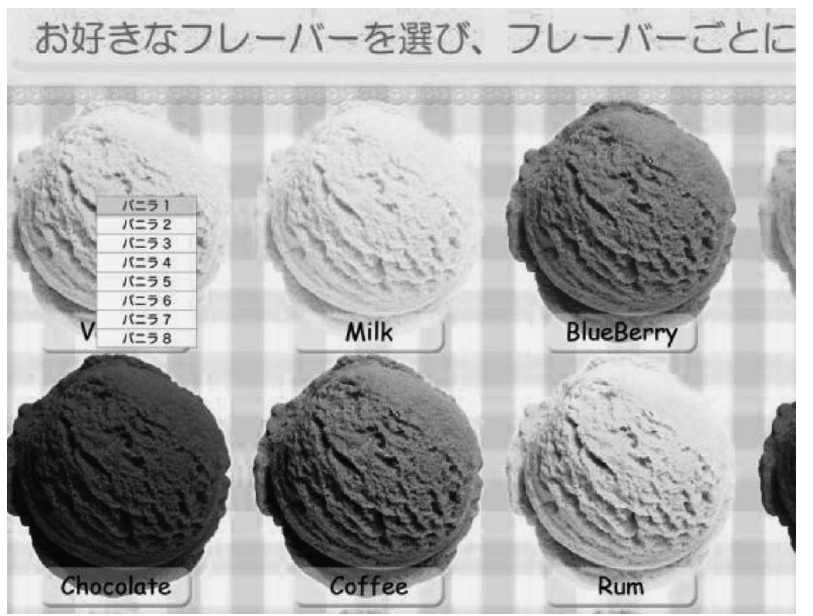

Fig. 6. Screen to Select an Ice Cream Flavor at Virtual Ice Cream Shop

が同時に提示されるというコンテンツである。ま た，鍵盤をひくだけでなく自動演奏モードも可能で ある.クロスモダリティを通じて体験者の情動面に おける想像性・創造性の喚起につながるようなイン タラクティブ・アートを意図して制作した. Figure 6 にアイスクリームのフレーバを選択している画面 を示す。このコンテンッでは, バニラ, ミルク, ブ ルーベリー，ミント，チョコレート，コーヒー， ラ ム酒，グリーンティ，バナナ，オレンジ，ストロベ リー，メロン等のフレーバを用意した. Figure 6 で はバニラフレーバを選択している。 このコンテンツ は“インタラクション”や Digital Olfaction Societyで既に実演を行った。この間の日本薬学会のシ ンポジウムのときに病院に入院している患者の方々 に楽しんでもらえるコンテンツはできないかと質問 されたが，病院内ではなかなか体験できない食の楽 しみをこのようなシステムで少しでも味わって頂け ないであろうか.

\section{5. まとめ}

本稿では，匂いセンサ及び嗅覚ディスプレイに関 して医薬に関連する研究を紹介した。 今後, われわ れはますます高齢化社会を迎えるが，香りがヒュー マンヘルスケアの分野に与える影響も少なくない. 匂いセンサは病気診断若しくはその予備テストに用 いることができれば，ヘルスケア分野に大いに貢献 できるであろう。また，嗅覚ディスプレイは，嗅覚 刺激発生装置として人の嗅覚検査のツールとしても 使える可能性がある。また，手術シミュレータに匂
いをつけたいという話もある．医薬の分野でも，匂 いセンサや嗅覚ディスプレイの研究を進める必要が ある．遠隔地で匂いを再現する技術, ${ }^{29)}$ 少ない要素 臭で多くの香りを近似する手法30)等も紹介したかっ たが別の機会に譲ることにする.

謝辞 口臭センサの研究の一部は東京医科歯科 大学植松 宏教授, 同大伊藤淳二氏との共同研究に よるものである.

\section{REFERENCES}

1) "Handbook of Machine Olfaction," ed. by Pearce T. C., Schiffman S. S., Nagle H. T., Gardner J. W., Wiley-VCH, Weinheim, 2003.

2) Janata J. Ed., Chem. Rev., 108, 327-844 (2008).

3) “Olfactory Display," ed. by Nakamoto T., Fragrance Journal Ltd., Tokyo, 2008.

4) "Human Olfactory Displays and Interfaces," ed. by Nakamoto T., IGI-Global, Hershey, 2012.

5) Abstracts Book of the 1st Digital Olfaction Society World Congress, April 2013, Berlin, pp. 1-46.

6) Kato A., "Kagaku juyo no Kagaku," ed. by Tohara K., Kagakudoujin, Kyoto, 2012, pp. 120-133.

7) Moriizumi T., Nakamoto T., "Sensor Engineering," Shokodo Co. Ltd., Tokyo, 1997, pp. 63-79.

8) Duda R. O., Hart P. E., Stork D. G., "Pattern Classification," Wiley-Interscience, New York, 2000.

9) Cristianini N., Taylor J. S., “An Introduction to Support Vector Machines and Other Kenelbased Learning Methods," KYORITSU SHUPPAN CO., LTD., Tokyo, 2005.

10) Tanada N., Sakurai T., Mitsuno H., Bakkum D., Kanzaki R., Takahashi H., IEEJ Transactions on Electronics, Information and Systems, 131, 35-41 (2011).

11) Lee S. H., Park T. H., Biotechnol. Bioprocess Eng., 15, 22-29 (2010).

12) Tonzetich J., Richter V. J., Arch. Oral. Biol., 9, 39-46 (1964).

13) Sasaya Y., Nakamoto T., IEEJ Transactions on Sensors and Micromachines, 126, 292-296 
(2006) .

14) Nakamoto T., "Handbook of Machine Olfaction, Odor handling and delivery systems," ed. by Pearce T. C., Scjffman S. S., Nagle H. T., Gardner J. W., Wiley-VCH, Weinheim, 2003, pp. 55-78.

15) Nakamoto T., Sukegawa K., Sumitomo E., IEEE Sens. J., 5, 68-74 (2005).

16) Geladi P., Kowalski B. R., Anal. Chim. Acta, 185, 1-17 (1986).

17) Nakamoto T., Oyo Buturi, 83, 12-17 (2013).

18) Nakamoto T., IEEJ Transactions on Sensors and Micromachines, 133, 178-183 (2013).

19) Nakamoto T., The Japanese Journal of Taste and Smell Research, 19, 147-156 (2012).

20) Nakamoto T., Journal of the Virtual Reality Society of Japan, 18, 8-11 (2013) .

21) Nakamoto T., Minh P. H. D., Proceedings of IEEE Virtual Reality Conference, Charlotte, March 2007, pp. 171-178.

22) Ariyakul Y., Nakamoto T., Trans. VRSJ, 15, 589-594 (2010).

23) Kurosawa M., Watanabe T., Higuchi T., Proceedings of IEEE Micro Electro Mechanical Systems, Amsterdam, February 1995, pp.
25-30.

24) Ariyakul Y., Aizawa T., Nakamoto T., IEEJ Transactions on Sensors and Micromachines, 133, 206-211 (2013).

25) Nakamoto T., Yoshikawa K., IEICE Transactions on Fundamentals of Electronics, Communications and Computer Sciences, E89-A, 3327-3332 (2006).

26) Nakamoto T., Otaguro S., Kinoshita M., Nagahama M., Ohnishi K., Ishida T., IEEE Comput. Graph. Appl., 28, 75-78 (2008) .

27) Nakamoto T., "Koukansurukagaku, How smells are recorded and reproduced," ed. by Bellsystem24, Bellsystem24, Tokyo, 2007, pp. 140-161.

28) Iseki M., Nakamoto T., IPSJ Interaction 2013, 3EXB-03.

29) Nakamoto T., Yamanaka T., "Intelligent Systems for Machine Olfaction: Tools and Methodologies, Odor reproduction with movie and its application to teleolfaction," ed. by Hines E., Leeson M., IGI Global, Hershey, 2011, pp. 126-152.

30) Nakamoto T., Ohno M., Nihei Y., IEEE Sens. $J .$, 12, 3225-3231 (2012) . 